GU J Sci, Part C, 6(1): 149-162 (2018)

Gazi Üniversitesi
Fen Bilimleri Dergisi
PART C: TASARIM VE TEKNOLOJI
dergipark.gov.tr/http-gujsc-gazi-edu-tr

\title{
Bir otomobil montaj işletmesinde enerji verimliliği artırıcı çözümlerin irdelenmesi
}

\author{
Fatma ÇANKA KILIÇ ${ }^{1}$, Muharrem EYIDOĞAN ${ }^{2}$, Süleyman SAPMAZ ${ }^{2, *}$ \\ ${ }^{1}$ Kocaeli Üniversitesi, Kocaeli Meslek Yüksekokulu, Elektrik ve Enerji Bölümü, İklimlendirme ve Soğutma Teknolojisi Programı, 41140, \\ Başiskele/KOCAELI \\ ${ }^{2}$ Kocaeli Üniversitesi, Teknoloji Fakültesi, Enerji Sistemleri Mühendisliği Bölümü, 41380,Umuttepe İzmit/KOCAELİ
}

$\ddot{O} \mathbf{z}$

$\underline{\text { Makale Bilgisi }}$

Başvuru: 27/07/2017

Düzeltme: 05/12/2017

Kabul: 27/12/2017

\section{Anahtar Kelimeler}

Otomobil montaj tesisi Enerji verimiliği

Özgül enerji tüketimi (SET)

Enerji tasarruf potansiyeli Boyahane

\section{Keywords}

Automobile assembly plant Energy efficiency Specific energy consumption (SEC) Energy saving potential Paint shop
Bu çalışmada, bir otomobil montaj tesisinin (Gövde (BiW) üretimi, boyama işlemi, şase ve aksesuar montaj işlemleri) enerji tüketimleri incelenmiştir. İmalat sürecinde enerjinin yoğun kullanıldığı alanlar tespit edilmiştir. Tesis genelinde, enerji tüketilen sistemlerde (boyahane, kurutma firınları, basınçlı hava, ısıtma ve soğutma sistemleri) verimliliğin artırılması için yapılabilecek çalışmalar ve otomobil montaj tesisinde kullanılan teknolojilerin enerji verimliliğine etkisi incelenmiştir. Tesiste gerçekleşen enerji tüketiminin büyük kısmı boyahanede gerçekleşmektedir. İncelenen tesiste kullanılan elektrik enerjisinin yaklaşı \% 050 'si ve doğalgazın yaklaşık \%70'i boyahanede tüketilmektedir. İncelenen tesis, $200.000 \mathrm{araç/yıl}$ üretim kapasitesine sahip haftada 6 gün ve günde 3 vardiya çalışmaktadır. Tesiste, araç başına özgül enerji tüketimi (SET) elektrik enerjisi için $\left(\mathrm{SET}_{\mathrm{e}}\right) 275 \mathrm{kWh}$, doğalgaz için $\left(\mathrm{SET}_{\mathrm{dg}}\right) 578$ $\mathrm{kWh}$ olmak üzere toplamda $853 \mathrm{kWh}$ olarak hesaplanmıştır. Yapılan incelemeler sonucunda tespit edilen tasarruf potansiyelleri hayata geçirildiğinde tesisin özgül enerji tüketimi elektrik enerjisi için \%1 ve 1sıl enerji için \%5,7 azalma sağlanacaktır.

\section{Examination of Energy Efficiency Increasing Measures in an Automobile Assembly Plant}

\begin{abstract}
In this study, energy consumption analysis was performed in a car assembly plant (Body-inWhite (BiW) productions, painting processes, chassis and accessory assembly processes). Examined automobile assembly plant has a production capacity of 200,000 vehicles per year by working six days a week and three shifts a day. Highly energy consuming processes are determined. Energy efficiency increasing opportunities in energy consuming systems (paint shop, drying ovens, compressed air, heating and cooling systems) and effects of current automotive assembly techniques on energy efficiency are examined. Most of the total energy in the studied plant is consumed in the paint shop. Considering annual energy consumption; paint shop is responsible for the $\% 50$ of total electrical energy and \%70 of total natural gas consumption. Specific energy consumption of plant is calculated as $853 \mathrm{kWh}$ (SET); $275 \mathrm{kWh}$ for electricity consumption $\left(\mathrm{SET}_{\mathrm{e}}\right)$, and $578 \mathrm{kWh}$ for natural gas $\left(\mathrm{SET}_{\mathrm{dg}}\right)$. By performing determined energy efficiency measures; SET of plant will reduce $\% 1$ for the $\mathrm{SET}_{\mathrm{e}}$, and $\% 5,7$ for $\mathrm{SET}_{\mathrm{dg}}$.
\end{abstract}

\section{GİRIŞ (INTRODUCTION)}

Fosil yakıtlara dayalı enerji üretimlerinin çevre üzerindeki olumsuz etkilerini gidermek üzere, günümüzde yenilenebilir enerjilere yönelik çalışmalar hızlandırılmış ve kapsamları genişletilmiştir. Gelişen teknoloji ile birlikte hızla artan enerji ihtiyacının karşılanmasında yenilenebilir enerjiler gerek maliyetlerinin yüksekliği gerekse teknik gelişimlerinin ve yaygınlaşmalarının istenilen seviyeye ulaşamamasından dolayı beklentileri karşılamada yetersiz kalmaktadır. Özellikle küresel anlamda çevrenin korunmasında da daha geniş çaplı olarak enerji portföyünde yer almaları gerekmektedir. Enerji verimliliği çalışmaları, *İletişim yazarı, e-mail: suleyman_sapmaz@hotmail.com 
enerji problemlerinin çözümlenmesinde ve maliyetlerin önemli oranlarda düşürülmesinde büyük katkılar sağlamaktadır.

Bir firma için ekonomik anlamda gelişmelerin en önemli göstergelerinden biri, üretim ve satış rakamlarını yükseltmektir. Bu amaçla yapılan çalışmaların karşısında ise ortaya çıkan rekabet şartları, üretici firmaları maliyetleri azaltmaya yöneltmektedir. Bilinçli tüketicinin çevresel anlamda üreticiden beklediği yeşil bir kimlik sunmak da büyük firmaların enerji ve pazarlama politikaları arasında giderek yerini almaya başlamıştır. İşçilik ve enerji maliyetlerini azaltmanın en etkin yöntemi ise üretimde verimliliğin arttırilmasidir.

Alternatif enerji kaynaklarının ekonomik ve teknik analizi gerçekleştirildiğinde fosil yakıtlı elektrik üretiminin uzun yillar devam edeceği öngörülmektedir ve bu yüzden, enerji üretim ve tüketimlerinde öncelikle yakın ve orta vadede acil çözüm önerilerinin hayata geçirilmesi gerekmektedir [1].

Enerji açısından tüketim koşulları incelendiğinde, günümüzde insanların kendi konfor şartlarını çevreye mal olan sonuçlarına rağmen değiştirmediği ve tüketimlerini kısmadığı görülmektedir. Bu yüzden üretici firmalar da her yıl artan taleplere karşıllk üretim hedeflerini yükseltmektedir.

Günümüzde otomotiv sanayii bünyesinde farklı pek çok malzeme ve üretim tekniklerine sahip çok sayıda tedarikçi bulunmaktadır. Modern bir araç; \%80'i dış tedarikçiler tarafından üretilen 10.000 adet parçadan oluşmaktadır [2]. Bir aracın toplam yaşam döngüsü boyunca gerçekleşen toplam enerji tüketimi dört kademede özetlenebilir: Ham malzeme işleme, araç imalatı, araç kullanımı ve araç geri dönüşümü. Otomotiv sanayiinin bu alt sektörlerini beraber değerlendirmek oldukça güçtür. Bu nedenle bu çalışmada binek araç montajının yapıldığı bir işletmede gerçekleşen enerji tüketimleri ve enerji tasarruf potansiyelleri değerlendirilmektedir.

Fysikopoulos ve ark. [3] otomotiv montaj hattında Body-in-White (BiW) alt gövde yapısını modelleyerek enerji tüketimi hesaplamışlardır. Çalışma sonucunda tesiste araç üretiminin maksimumu olduğu 161.-240. günlerde enerji tüketimini minimum $(68,9 \mathrm{MJ})$ olduğu görülmüştür. Bunun sebebi olarak kapasite kullanımın artması ile makinelerin verimliliklerin artması gösterilmektedir. Kaynak çalışmasına ait simülasyonda BiW üzerinde toplam 4.474 kaynak noktası olduğu ve bunun \%49,6 sinın alt gövdede olduğu göz önünde bulundurularak yapılan 2 yıl süreli simülasyon çalışması ile $73 \mathrm{MJ} /$ alt gövde enerji tüketimi gerçekleşeceği hesaplanmıştır.

Rivera ve ark. [4] otomotiv boyama ünitesinde, malzeme ve prosesle ilgili geliştirmelerle elde edilebilecek enerji kazanımlarını ortaya koymuşlardır. Çalışmada, boyama kademesinde kullanılan boya türleri (su bazlı, solvent bazlı vb.) ve proses şartlarında (firın sıcaklığı, boyama ekipmanlarının türü vb.) değişimlerle gerçekleştirilebilecek enerji verimliliği artışları literatür taraması olarak verilmiştir. Önerilen çözümler teorik ve uygulama ile karşılaştırılmıştır. Çalışma ile uygulama yapılan tesiste mevcut duruma kiyasla boya prosesinde; boya hazırlamada \%10, astar boya uygulamasinda $\% 6$, temel boya uygulamasında $\% 12$, vernik uygulamasında $\% 12$, ön kurutma işleminde $\% 32$, kurutma işleminde $\% 22$, su arıtma işleminde $\% 6$ elektrik enerjisi tasarruf potansiyeli olduğu ortaya konulmuştur.

Chan Oh ve ark. [5] otomotiv sektörü için farklı kuruluşlar tarafından verilen enerji verimliliği artışına yönelik yapısal teknik geliştirme desteklerinin analizi için kullanılmak üzere stokastik ve deterministik sınır analizleri (SFA ve DEA) yöntemlerini kullanarak karşılaştırma işlemi gerçekleştirmişlerdir. Modelleme sonucunda çeşitli enerji verimliliği programlarının etkinliklerinin karşılaştırılması amaçlanmıştır. SFA modeli temelli çalışmalarda 41,73 \$/araç maliyet kazancı sağlanabileceği hesaplanmiştır.

Schlei-Peters ve ark. [6] endüstriyel su ve enerji tüketiminin birbirine hangi oranda bağlı olduğunu ortaya koymak için bir model geliştirmişlerdir. Geliştirilen model bir otomotiv imalat tesisi soğutma kulesinde test edilmiştir. Modelin test edilmesi için enerji ve su tasarrufu sağlayacak iki senaryo geliştirilmiştir. Model kullanılarak bu iki senaryonun müstakil kazanımları ve her ikisinin beraber kullanılmasıyla elde edilecek kazanımlar hesaplanmıştır. Baz enerji tüketimi $373.222 \mathrm{kWh}$ olan sistemde birinci senaryo ile $328.454 \mathrm{kWh}$, ikinci senaryo ile $359.833 \mathrm{kWh}$, her iki senaryonun beraber uygulanması ile $318.014 \mathrm{kWh}$ enerji tüketimi gerçekleşeceği ortaya konmuştur

ABD Enerji Bakanlığı (DOE) Endüstri Teknolojileri Programı (ITP), ABD Otomotiv Araştırmaları Konseyi (USCAR) ile işbirliği kapsamında "Otomotiv İmalatında Enerji Tüketiminin Azaltılması Yol 
Haritası" başlıklı yayını hazırlamışlardır. Bu çalışmanın yayınlanması otomotiv üretimi ve buna bağlı tedarik zincirinde enerji tüketiminin azaltılması ile ilgili firsatların anlaşılması için odaklanmış bir gayreti ifade etmektedir. Açıkça görülmektedir ki firsatlar çeşitli ve endüstrinin her alanını kapsamaktadır. Yol Haritasında $\mathrm{BiW}$, iç aksam, otomotiv boya prosesi, güç ünitesi ve gövde elemanları, nihai montaj, tesis yardımcı işletmeleri incelenmiştir. Ayrıca inovasyonla geliştirilmesi gereken enerji verimliliği alanları da okuyucular için derlenmiş̧tir [7].

Literatürde yapılan araştırmalarda, otomobil montaj tesisinde enerji tüketen sistemler ayrı ayrı ele alarak incelemiş ve ayrıca, bu sistemlerin enerji tasarruf potansiyellerini ortaya koyan herhangi bir çalışmaya rastlanamamıştır. Bu doğrultuda eksik görülen bu incelemeleri literatüre katmak üzere yapılan bu çalışmada dikkatle ele alınan enerji tüketim sahalarına ait tasarruf potansiyelleri değerlendirilerek sonuçları her kesimden araştırmacıların bilgisine sunulmuştur.

\section{ARAÇ ÜRETIM PROSESİ (THE PROCESSES OF VEHICLE MANUFACTURING)}

Temel olarak otomobil üretimi dört kademe içermektedir bunlar sırasıyla, parça imalatı, araç gövde imalatı şase imalatı ve montajdır.

Araç endüstrisi pek çok parçayı kendisi üretmektedir. Bazı parçalar ise bağlı şirketler tarafından üretilmektedir. Motor alüminyum ya da demir döküm olarak üretilmekte ve daha sonra motor üretim tesislerinde işlenmektedir. Metal döküm endüstrisi bilindiği üzere enerji yoğun bir sektördür.

Otomobil ve diğer araç gövdelerinin üretiminde plastik ve alüminyum parçaların kullanımı artmakla birlikte gövde çoğunlukla çelik sacdan imal edilmektedir. Düşük maliyet ve iyi şekillendirilebilirdik gibi bazı teknik özelliklere bağlı olarak çeşitli çelik alaşımları da kullanılmaktadır. Bazı bölümler için ise fiberglas, alüminyum ve plastik malzemeler kendilerine has özellikleri nedeniyle tercih edilmektedirler.

Şase aracın asıl yapısıdır. Genellikle araç üretiminde çelik çerçevenin oluşturduğu iskelet üzerinde tekerlek aks sistemi, güç dağıtım sistemi, yönlendirme mekanizması ve süspansiyon elemanları montaj edilmektedir. Günümüzün küçük araba tasarımlarında araç şasesinin ve gövdesinin tek parça üretimine yönelik yeni bir eğilim ortaya çıkmıştır.

Boya araç gövdesini korumak için uygulanmaktadır. Bu amaca uygun olarak özel astarlama ve boyama işlemleri uygulanmaktadır. Araç gövdeleri öncelikle yüzeydeki yağ ve diğer bileşenlerin giderilmesi için temizlik banyosuna daldırılmaktadır. Bu işlemden sonra araç gövdesi gerekli görsel kalite ve sertliği sağlayacak olan birbirini takip eden bir dizi boya işleminden geçmektedir. Hem enamel hem akrilik vernik kullanılmaktadır. Akrilik vernik su bazlıdır ve sis oluşturan uçucu organik bileşen (VOC) çıkışını azaltmaktadır. Elektrostatik boya prosesi boya spreyine elektrostatik gerilim $(50-80 \mathrm{kV})$ uygulanarak araç gövdesine iletilmesi ile tüm araç yüzeyinde homojen bir boya dağılımı sağlanmasına yardımcı olmaktadır. Konveyörlü firınlar araç üzerindeki boyanın kurutulması için kullanılmaktadır. Kızılötesi (IR) kurutma gibi farklı teknolojiler ile enerji tasarrufu sağlanmakta, kuruma işlem süresi kısaltılmakta ve kurutucu hacmi küçültülmektedir. Boya işlemi tamamlandıktan sonra araç gövdesi boyada meydana gelebilecek hataların tespiti ve gerekli ise düzeltilmesi için muayene edilmektedir.

Otomobil montajında, temel olarak iki montaj hattı bulunmaktadır: gövde ve şase. Gövde montaj hattında paneller birbirine kaynakla monte edilir, kapı ve pencereler monte edilir, gövde boyanır ve aksesuar montajı, iç kablolama işlemleri yapılır. Şase montaj hattında yaylar, tekerler, direksiyon tertibatı ve motor, transmisyon ve tahrik milinden oluşan güç aktarma mekanizması fren ve egzoz sisteminden oluşan çerçeveye bir araya getirilir. İki hat gövdenin şaseye monte edileceği noktada birleşirler. Bu prosesten farklı olarak "birimleştirilmiş montaj" yaklaşımında gövde ve şase tek bir hatta monte edilmektedir [8].

\section{OTOMOBIL MONTAJ TESISINDE ENERJI TÜKETIMI VE VERIMLILIKK ARTIRICI FIRSATLAR (ENERGY USAGE AND EFFICIENCY INCREASING OPPORTUNITIES IN VEHICLE ASSEMBLY PLANTS)}

Araç üretimi enerji ve malzeme yoğun bir süreçtir. Bir aracın yaşam döngüsü malzeme ekstraksiyonu/madencilik, malzeme ve bileşen üretimi, montajı, ürün nakliyesi, kullanımı, bakımı ve yaşam döngüsü sonu gibi farklı adımlar içermektedir [9]. 
Motorlu araç montaj tesislerinde enerji, tesis çapında çeşitli nihai tüketim noktalarında kullanılmaktadır. Sahada kullanılan birincil enerji kaynakları; elektrik, buhar, doğalgaz ve basınçlı havadır. Toplam enerji bütçesinin 2/3'ünü elektrik enerjisi teşkil etmektedir. Yakıtlar ise özellikle boya kabinleri için sicak su ve buhar üretimi ve boya kurutma firınlarında tüketilmektedir [8].

Otomobil montaj tesislerinde enerji, çeşitli nihai kullanım alanlarında tüketilmektedir. Yakıtlar temel olarak ortam 1sıtması, buhar üretimi ve boya kurutma firınlarında kullanılmaktadır. Bazı tesislerde motor ve diğer parçaların üretimi için dökümhaneler de bulunabilmektedir. Elektrik ise basınçlı hava, aydınlatma, sac şekillendirme, iklimlendirme, boyama, kaynak ve malzeme nakliyesi gibi imalatın başından sonuna kadar çeşitli uygulamalarda kullanılmaktadır. Enerji tüketimimin dağılımı tesise özgüdür ve tesiste gerçekleştirilen işlemlere bağl1 olarak değişiklik göstermektedir. Otomobil montaj tesislerinde toplam enerji tüketimi, toplam maliyet içerisinde \%1'lik yer tutmakla toplam imalat sürecinde oldukça küçük bir maliyet faktörüdür.

Yakıt temel olarak ortam 1sıtması ve araç boyama hattında nem ve sicaklık kontrolü için gerekli iklimlendirme sistemlerinde tüketilmektedir. Almanya'da tesis yakıt tüketiminin \%50-60’l1k kısmı boyahanede gerçekleşmektedir [10]. Yakıt ayrıca boyama prosesinden kaynaklanan uçucu organik bileşenlerin (VOC) termal oksidasyonu için kullanılmaktadır.

$\mathrm{Bu}$ çalışmanın amacına uygun olarak otomotiv imalat prosesinde büyük miktarda enerji sarfiyatının gerçekleştiği montaj işlemlerine odaklanılmıştır. Araç montaj tesislerinde, tesis performansını düşürmeden veya yükselterek uygulanabilecek pek çok enerji verimliliği artış firsatı bulunmaktadır. Aşağıda; bir araç üretim prosesinde gerçekleştirilebilecek enerji verimliliği artırıcı önlemler; kullanıldığı sistemlere (su ve buhar kazanları, basıcçlı hava, boya işlemi, chiller üniteleri ve pompa sistemleri vb.) tasnif edilmiş olarak verilmektedir

\section{1. Örnek Bir Otomobil Üretim Tesisinin Enerji Görünüm Değerlendirmesi (Energy Outlook Evaluation of a Sample Automobile Production Plant)}

Örnek çalışma, 200.000 araç/y1l üretim kapasitesine sahip bir otomobil üretim tesisinde gerçekleştirilmiştir. Çalışma yapılan otomobil üretim tesisi Türkiye'nin Marmara bölgesinde bulunmaktadır. Tesisin bulunduğu bu bölgede aşırı soğuk ve aşırı sıcak iklim koşullarına sahip değildir. Tesise gelen sac malzeme kullanılarak Body in White $(\mathrm{BiW})$ üretimi gerçekleştirilmektedir. BiW üretiminde presler ve kaynak robotları yoğun enerji tüketen sistemlerdir. Tesis enerji tüketiminin büyük bölümü boyahanede gerçekleşmektedir. Montaj hattında ise tedarikçilerden gelen motor bloğu ve elemanları ile iç aksesuar ekipmanları gövdeye yerleştirilmektedir. Gerçekleştirilen enerji analizi çalışması BiW üretimi ile otomotiv montaj sürecini kapsamaktadır. Tesisin elektrik ve doğalgaz tüketiminin bölümler bazında dağılımı Şekil 1. a) ve b)'de verilmektedir.

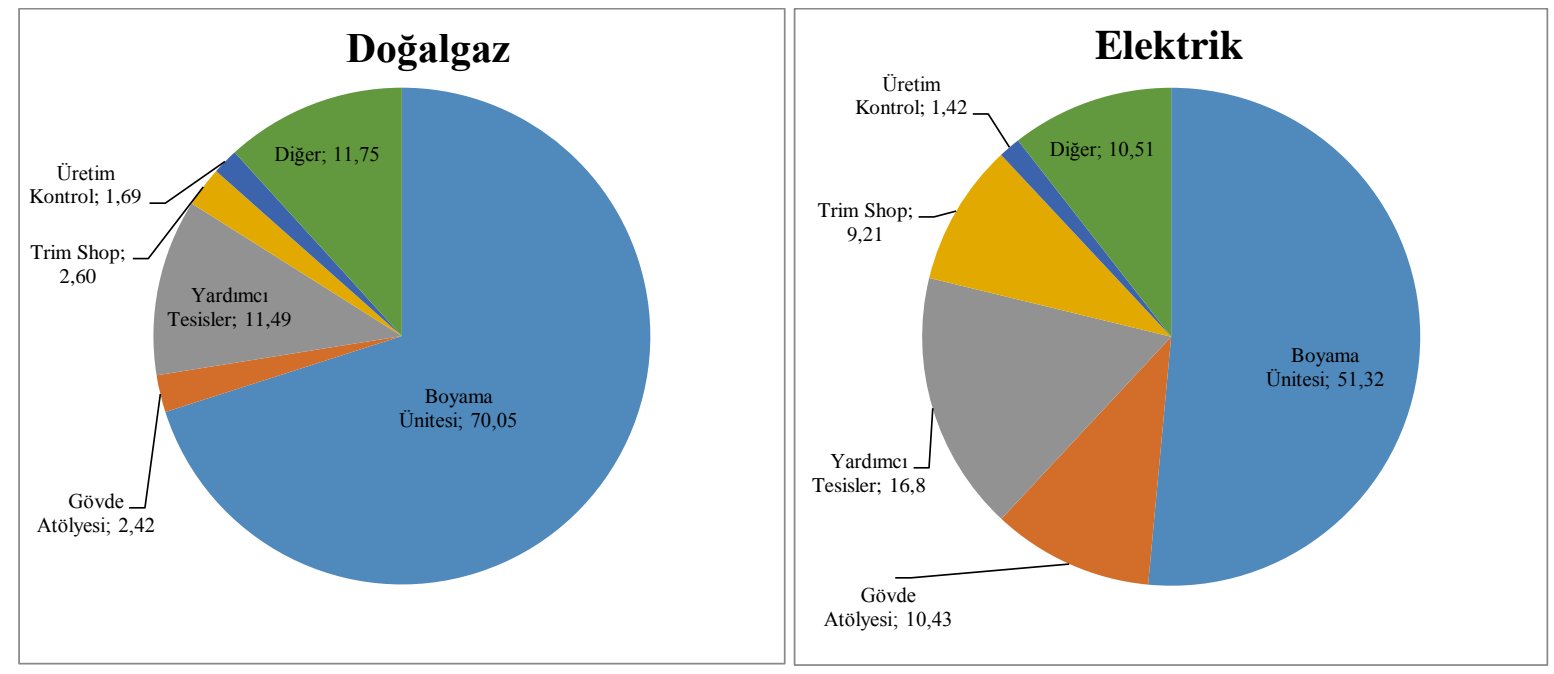

Şekil 1. İncelenen tesisin doğalgaz ve elektrik tüketimlerinin genel dă̆glımı. 
Tesisin mevcut yıllık çalışma düzeni ile araç başına özgül enerji tüketimi (SET) elektrik enerjisi için $\left(\mathrm{SET}_{\mathrm{e}}\right) 275 \mathrm{kWh}$, doğalgaz için $\left(\mathrm{SET}_{\mathrm{dg}}\right) 578 \mathrm{kWh}$ olmak üzere toplam $853 \mathrm{kWh}$ olarak hesaplanmıştır. Farklı tesislerde; özgül enerji tüketim verilerinin çeşitliliği üretim metotları, üretilen parçalar, üretilen araç türü (büyüklüğü), iklim şartları vb. koşullardan etkilenmektedir. Literatürde dokuz farklı otomotiv üreticisine ait 2012 ve 2013 yıllarına ait özgül enerji tüketim değerleri $1600 \mathrm{kWh}$ ve $3500 \mathrm{kWh}$ arasında verilmektedir. Çalışmaya göre farklı üreticilere ait tüketimlerin değişken olması sistem sınırlarının farklı alınmasından kaynaklanmaktadır[11].

\subsection{Su ve Buhar Kazanları (Steam and Water Boilers)}

Buhar ve sıcak su kazanlarında enerji verimliliğini etkileyen başlıca faktörler; eksik yanma, fazla hava, baca gazında su buharı nedeniyle olan 1sı kaybı, baca gazı sıcaklığı, yakıt cinsi, brülörler, kazan yükü, kazan yüzeyinden olan 1sı kayıpları, 1sıtıcı yüzey kirliliğ̈i, egzoz gazı sıcaklığı şeklinde sıralanabilir. Ayrıca, buhar kazanlarında yapılan blöf miktarı da buhar kazanında enerji verimliliğini etkileyen bir faktördür.

Çalışmaların yapıldığı üretim tesisinde, buhar ve sıcak su; boyahane eşanjörlerinde, HVAC ünitelerinde, kış aylarında üretim yapılan kapalı alanların ssıtılmasında, idari bina ve sosyal tesislerin 1sitılmasında ve diğer ihtiyaç duyulan yerlerde kullanılmaktadır.

$\mathrm{Bu}$ otomobil üretim tesisinde, buhar ihtiyacı iki adet 4 bar basınçta 3,5 ton/saat buhar üretim kapasiteli buhar kazanları ve 2 ton/saat kapasiteli 6 bar basınçta buhar üreten iki adet buhar kazanı tarafından karşılanmaktadır. Buhar kazanlarında üretilen buhar, boyahane fosfat eşanjörü, ön yă alma tank eşanjörleri, metal tozu ayırma ünitesi eşanjörü ve HVAC ünitesinde kullanılmaktadır.

Tesiste sıcak su ihtiyacı ise iki adet sıcak su kazanından karşılanmaktadır. Bu sıcak su kazanlarında yaklaşık $50^{\circ} \sim 60^{\circ} \mathrm{C}$ sıcaklıkta sıcak su elde edilmektedir. Kazanlardan elde edilen sıcak su, fan coiller yardımıyla üretim yapılan kapalı alanlar, idari bina ve sosyal tesislerde ortam 1sıtması için kullanılmaktadır.

İncelenen otomobil üretim tesisinde, kazanlarda enerji verimliliğine yönelik yapılan çalışmalarda kazanların baca gazı analizleri yapılmıştır. Doğalgaz yakıtlı buhar ve sıcak su kazanlarının baca gazında kabul edilebilir oksijen oranı \%1,5-2,5 civarında olmalıdır. Kazanların egzoz gazlarında CO emisyonu oluşmaksızın $\mathrm{O}_{2}$ miktarı yüksek çıkar ise bu durum kazanın hava fazlalık katsayısının yüksek olduğunu göstermektedir. İncelenen otomobil üretim tesisinde 4 bar basınçlı buhar kazanı baca gazı analizinde $\mathrm{O}_{2}$ miktarı \%5,2 olarak analiz edilmiştir. Kazan brülöründen hava/yakıt oranı ayarlanarak, kazanın optimum hava/yakıt oranıyla çalıştııılması durumunda doğalgaz tasarrufu sağlanacaktır. Bu kazanda hava/yakıt oranının optimizasyonu ile sağlanacak tasarrufu $146.610 \mathrm{kWh} / \mathrm{y} 1 \mathrm{l}$ ve bu tasarrufun mali değeri yaklaşı $5.563 \$ / y 11$ 'dir.

Kazanlarda yapılan egzoz gazı sıcaklık ölçümünde, 6 bar basınçlı buhar kazanlardan birinde baca gazı sıcaklığ $197^{\circ} \mathrm{C}, 6$ bar basınçlı diğer buhar kazanında ise baca gazı sıcaklığı $213{ }^{\circ} \mathrm{C}$ olarak ölçülmüştür. $\mathrm{Bu}$ iki kazanın egzoz çıkışına ekonomizer konularak kazana beslenen suyun ön 1sıtılmasıyla kazanda enerji verimliliği artırılabilir. Doğalgaz yakıtlı buhar kazanlarının egzoz gazı sıcaklığı $120 \sim 130{ }^{\circ} \mathrm{C}^{\prime}$ ye kadar düşürülebilir. $\mathrm{Bu}$ iki buhar kazanına ekonomizer uygulanması ile elde edilecek toplam enerji tasarrufu $121.968 \mathrm{kWh} / \mathrm{y}$ ll ve tasarrufun mali değeri 4.629 \$/yıl'dır. Bu iki kazan için ekonomizer yatırım maliyeti toplam olarak 25.034 \$ ve yatırımın basit geri ödeme süresi 5,41 y1l'dır.

İncelenen tesiste sıcak su kazanlarında, kazan verimliliğine yönelik yapılan çalışmalarda sıcak su kazanı egzoz gazı analizinde $\mathrm{O}_{2}$ miktarı \%15,3 olarak ölçülmüștür. Brülör ayarı yapılarak egzoz gazındaki $\mathrm{O}_{2}$ miktarı \%3,5'e düşürülmüştür. Bu sıcak su kazanının brülörü hassas hava/yakıt ayarı yapılmaya elverişli olmadığı için egzoz gazındaki $\mathrm{O}_{2}$ miktarı $\% 1,5$ seviyelerine düşürülememiştir.

İncelenen tesiste bulunan sıcak su kazanlarında baca gazı sıcaklığı $130 \sim 140{ }^{\circ} \mathrm{C}$ aralığında ölçülmüştür. Kazanların çıkıșına ekonomizer konularak, baca gazı içerisindeki su buharının yoğuşturulmasıyla egzoz sicaklığının $60 \sim 70^{\circ} \mathrm{C}^{\prime}$ lere düşürülmesi mümkündür. Böylece egzoz gazı içerisindeki su buharının buharlaşma gizli ısısından da faydalanarak önemli oranlarda yakıt tasarrufu sağlanabilir. 
Sıcak su kazanları için ekonomizer uygulaması ile elde edilecek toplam enerji tasarruf miktarı 144.100 $\mathrm{kWh} / \mathrm{y}$ ll ve enerji tasarrufunun mali değeri 5.444 \$/yıl'dır. Bu kazanlar için ekonomizer yatırım maliyeti 27.814 \$ ve basit geri ödeme süresi 5,09 yıl'dır.

Kazanlarda atık 1S1 geri kazanımı ve hava/yakıt oranının optimizasyonu ile $412.678 \mathrm{kWh} / \mathrm{y} 1 \mathrm{l}$ enerji tasarrufu ve 15.636 \$/yıl mali tasarruf imkânı sağlanabilir.

\subsection{Buharsız Fabrika Çalışmaları (The studies for the factory without steam)}

Endüstriyel üretim hattında yer alan çeşitli işlemler için gerekli enerjinin sağlanmasında; elektrik, buhar, basınçlı hava gibi enerji taşıyıcı ortamlar kullanılmaktadır. Elektrik enerjisi doğrudan üreteçlerden alınıp tüketim yerlerine kablolar vasıtasıyla iletilmektedir. Buhar ve basınçlı hava ise genellikle sahada yer alan sistemler yoluyla üretilmekte ve borular vasıtasıyla tüketim sahasına taşınmaktadır. $\mathrm{Bu}$ iki kaynağın üretimi, kullanım yerine taşınması ve son tüketiminde genellikle kayıplar gerçekleşmektedir.

Buhar üretiminin sürdürülebilir olarak devam etmesi için detaylı ve hassas bir su hazırlama işlemi gerekmektedir. Bu hazırlama işleminden çıkan su çeşitli kapasite ve özellikteki buhar üreteçlerinde 1s1 transferi ile buhar fazına geçirilmektedir. Buhar sisteminin çalışma basıncına göre kazanlarda ve hatlarda çeşitli emniyet tedbirleri ve basınç düzenleyiciler kullanılması gerekmektedir. Üretilen buhar, tüketim noktalarına miktar ve kalite açısından kayıpsız şekilde ulaştırılmalıdır. Buhar hattında gerçekleşen sızıntılar sanal tüketim oluşturmakta, üretim ve tüketim noktası arasında basınç kaybına da neden olmaktadır. Hatlarda mevcut 1s1 izolasyonlarının bozuk/yetersiz olmas1 sonucunda ise enerji kayb1 yaşanmaktadır. $\mathrm{Bu}$ nedenlerle buhar enerjisi, üretimden tüketim noktasına ulaşıncaya kadar oldukça maliyetli, zahmetli ve sürekli takip gerektiren bir kaynaktır.

Buhar ile 1sı taşınımı (eşanjör ile gaz ve/veya sıv1 1sıtılması amaçlı kullanımı) buhar kazanı ve tesisatlarındaki kayıplar nedeniyle brülör ile doğrudan 1sıtma amaçlı kullanımına göre düşük verimli $(\% 50 \sim 70)$ bir uygulamadır. Bazı işletmeler bu verimsizliği ortadan kaldırabilmek için alternatif çözümlere yönelmektedir. Bu çözümlerden biri ise düşük sıcaklık gereksinimi olan noktalarda yoğuşmalı sıcak su kazanlarının kullanılması ve yüksek sıcaklık gereken noktalarda da brülörle yakıtın yakılması sonucu açığa çıkan ısının kullanılmasıdır. Buharın kullanılmadığı bu tür tesisler, buharsız fabrikalar olarak isimlendirilmektedir.

Doğalgazın yakıt olarak nakliyesi kolaydır, kullanımı her geçen gün daha da yaygınlaşmaktadır, doğalgaz için kullanılan yakma ekipmanlarının ilk yatırım maliyetinin düşmesi ve işletme verimliliğin artması sayesinde 1sıl enerjinin yerinde üretimi çok daha ekonomik olmaktadır. Buna göre 1sı ihtiyacı; talebin olduğu bölgelerde yakıtın doğrudan yakılması ile sağlanmaktadır. Ortam havası, doğrudan yakma sistemlerinde 1sıtılabildiği gibi, yüksek sıcaklığa dayanıklı 1Sı transfer yağları da enerji taşınmasında kullanılabilir. Buharsız fabrika konsepti sayesinde;

- Pahalı su hazırlama sistemi yatırımlarına ihtiyaç duyulmamaktadır.

- $\quad$ Hatlarda oluşacak 1sı, basınç ve buhar kayıplarının önüne geçilmektedir.

- Isı ihtiyacı yerinde ve hızlı şekilde sağlanabilmektedir.

Otomobil üretiminde de buharsız fabrika uygulamaları kullanılmaya başlamıştır. Böylelikle buhar kullanımından kaynaklanan verimsizlikler azaltılmaya çalışılmaktadır. Örneğin HVAC sistemlerinde boya kabinlerine gönderilen havanın 1sıtılması için yoğuşmalı kazanlarda 1sıtılan su ve serpantin sistemi kullanılmaktadır ve bu sayede \%10-15 doğalgaz tasarrufu sağlanabilmektedir.

\subsection{Basınçlı Hava (Compressed Air)}

İyi tasarlanmış bir basınçlı hava sisteminde kompresör giriş gücünün ancak \%10'u faydalı işe dönüştürülebilmektedir. Bir enerji taşıyıcısı olan basınçlı hava, bu verim düşüklüğünden dolayı, zorunlu olmadıkça proseslerde kullanımı özellikle elektrik ve buhar gibi alternatifleri varsa tercih edilmez.

Basınçlı hava sistemlerinde enerji verimliliğin arttırılması için alınabilecek önlemler; sızıntıların önlenmesi, yüksek verimli motorların kullanılması, kompresör çalışma basıncının düşürülmesi ve kompresör emiş havasının sıcak kurutma odası yerine nispeten daha soğuk olan dış ortamdan alınması 
olmak üzere dört başlıkta listelenebilir. Basınçlı hava sisteminde meydana gelen sızıntılar toplam hava üretiminin \% 25 'ine kadar ulaşabilmektedir. Bununla beraber kabul edilebilir sızıntı oranı kompresör çıkış debisinin \%10'u kadardır[12].

Aynı zamanda, kompresör giriş gücünün $\% 85$ 'ine ulaşan oranlarda kompresör atık 1sısı geri kazanılabilir. $\mathrm{Bu}$ kazanım ara soğutucu, son soğutucu ve yağ soğutucusunda dolaşan isının kullanılması ile gerçekleştirilebilir. Otomotiv sektörü gibi basınçlı havanın yoğun şekilde kullanıldığı üretim tesislerinde, kompresör atık ısısının etkin şekilde kullanımı ile büyük miktarda enerji tasarrufu sağlanabilmektedir[13].

Basınçlı hava; temiz, güvenli ve emniyetli bir enerji taşıyıcı olduğu için delme işlerinde, kontrol valflerinde, hava motorlarında, temizleme amaçlı hava tabancalarında, boya spreylerinde vb. birçok alanlarda kullanılmaktadır.

İncelenen otomobil üretim tesisinde, basınçlı hava ihtiyacı sekiz adet kompresörden karşılanmaktadır. Tesisteki beş adet kompresör 7 bar ve üç adet kompresör ise 9 bar basınçta çalışmaktadır. Üretilen havanın kurutulması için beş adet soğutmalı kurutucu bulunmaktadır. İncelenen tesiste basınçlı hava sisteminde sızıntı kayıplarının giderilmesi ve kompresör yük profillerinin optimizasyonu ile enerji verimliliği artışı sağlanabilir.

İncelenen otomobil üretim tesisinde ultrasonik dedektörle basınçlı hava taraması yapılarak sızıntı hava kayıpları tespit edilmiştir. Tesiste, Gövde bölümünde tespit edilen toplam 74 kaçak noktasının (boru hatlarında ve boru bağlantılarında, valflerde, selenoidler vb. ekipmanlarda) bakımı yapılarak 209.010 $\mathrm{kWh} / \mathrm{y} 1 \mathrm{l}$ enerji ve 14.891 \$/y1l mali tasarruf elde edilebilir. Trim Bölümünde tespit edilen toplam 56 kaçak noktasının bakımı yapılarak $134.030 \mathrm{kWh} / \mathrm{y} 1$ enerji 9.548 \$/yıl mali tasarruf sağlanabilir.

9 bar basınçtaki hava talebini karşılamak için çalışan iki kompresörden biri olan $90 \mathrm{~kW} l 1 \mathrm{k}$ kompresör frekans konvertörü kontrollüdür ve 75 kW'lık kompresör yük-boş kontrollüdür. $90 \mathrm{~kW} l 1 \mathrm{k}$ kompresörün kapasitesi yeterli olmadığında $75 \mathrm{~kW}$ 'lık kompresör devreye girmektedir. Yapılan ölçümlerde 75 kW'lık kompresörün güç profili çıkarılarak analizler gerçekleştirilmiştir. Analiz sonuçları kompresörün çok sık devreye girip çıktığını göstermektedir. Kompresörün yüksüz enerji tüketimi $25 \mathrm{~kW}$ yüklü enerji tüketimi ise $92 \mathrm{~kW}$ olarak ölçülmüştür. Yapılan incelemelere göre kompresörün yıllık çalışma süresinin \%60'ında boşta çalıştığı tespit edilmiştir. Bu problemin çözümü için $75 \mathrm{~kW}$ 'lık kompresör yerine $132 \mathrm{~kW}$ gücünde VSD (Değişken Hız Sürücüsü) kontrollü bir kompresör kullanılabilir. 132 kW'lık kompresör tek başına değişken hava debi ihtiyacını karşılayarak diğer kompresörün yükte boşta çalışması önlenmiş olacaktır. Böylelikle, 75 kW'lık kompresör boşta çalıştırılmadığından enerji tasarrufu sağlanacaktır.

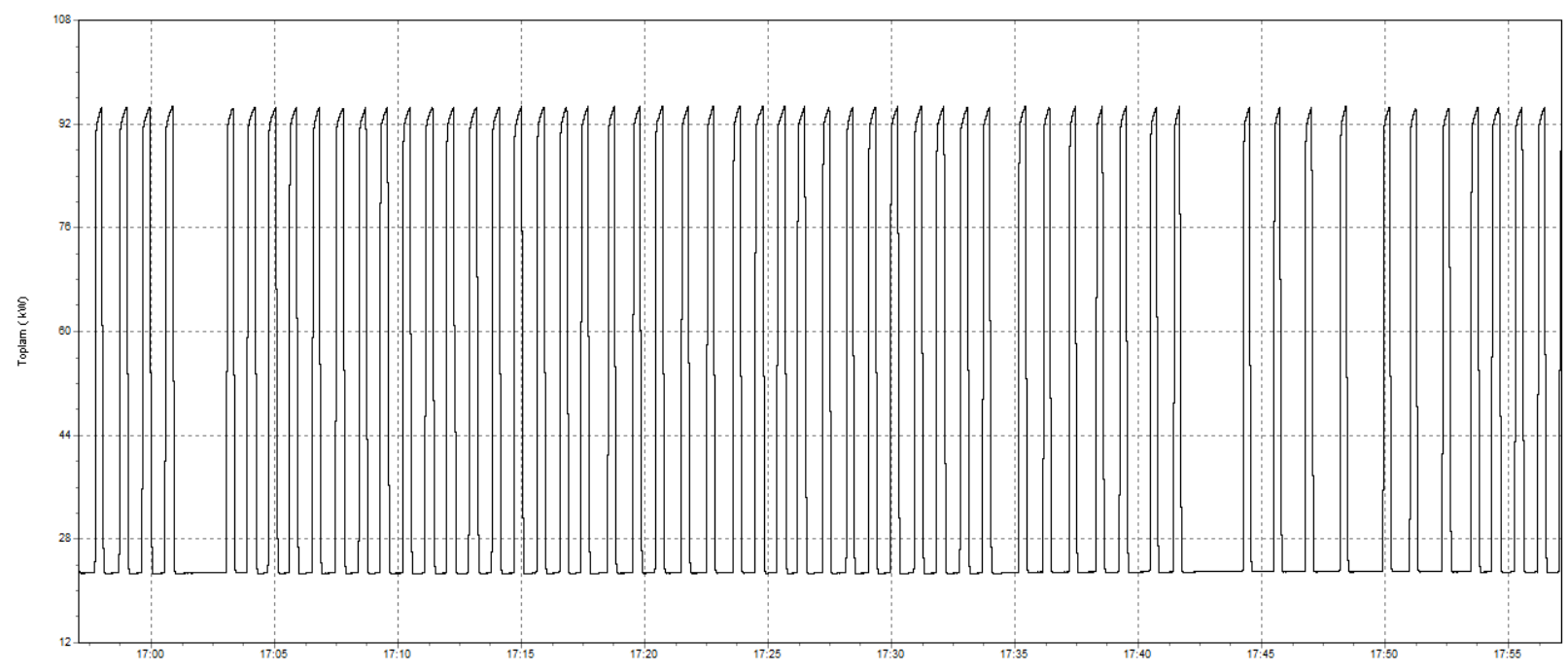

Şekil 2. 75 kW kompresör yük profili ve yüklü/boşta gü tüketimleri

\subsection{Boyahane HVAC Fanları (HVAC Fans of the Paint Shop)}

Boya işleminin kaliteli şekilde gerçekleştirilebilmesi için boyama kabinlerinde uygun iklim şartlarının sağlanması gerekmektedir. Bu amaçla boyahanelerde HVAC üniteleri kullanılmaktadır. Boyahane HVAC 
fanları, boyama kabinlerindeki işlem sırasında havaya karışan boya partiküllerini ortamdan uzaklaştırmak ve atmosferden aldığı taze havayı iklimlendirerek boyama kabinlerine göndermek için kullanılmaktadır. HVAC üniteleri taze havayı iklimlendirmek için sirasıyla filtreleme, ön 1sıtma, soğutma, nemlendirme ve son 1sıtma işlemlerini ihtiyaca göre yerine getirmektedir.

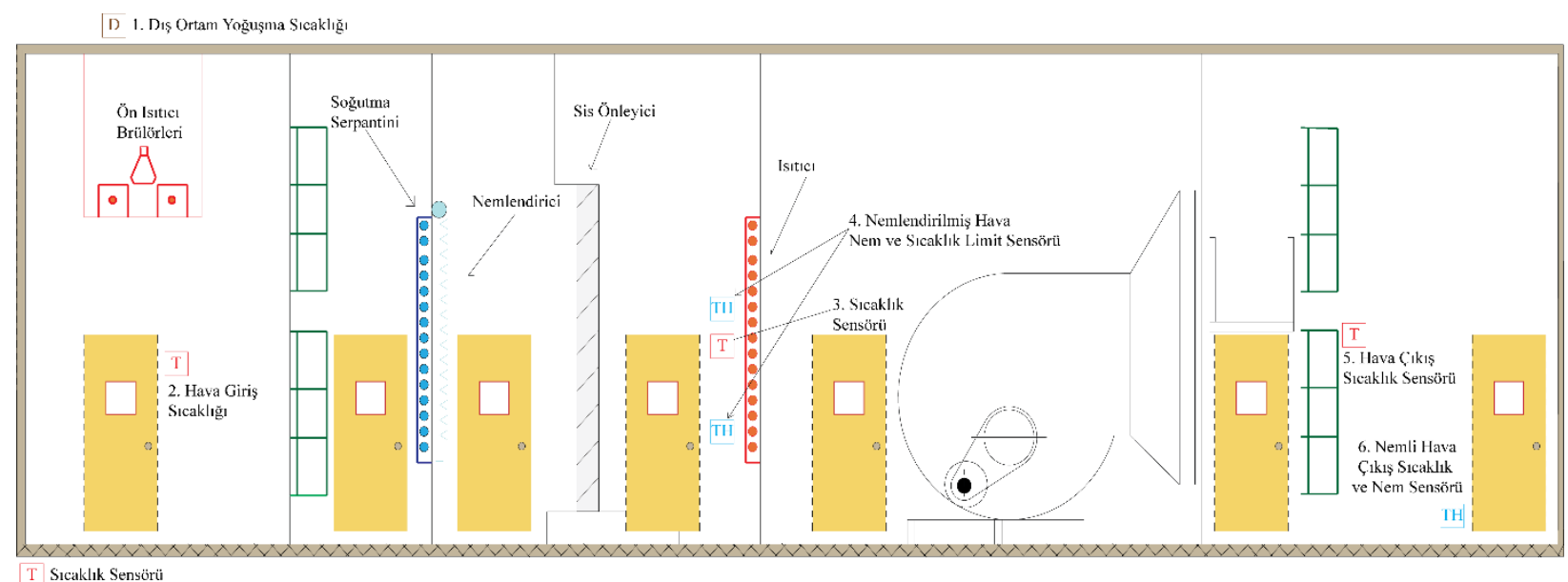

Şekil 3. Örnek bir boyahane HVAC ünitesi şematik resmi

İncelenen tesiste, fan motorlarının tamamında hız sürücüsü bulunmakta, fakat fan motorlarının devirleri sistemden alınan anlık ölçüm bilgisine göre ayarlanmamaktadır. Sürücü frekansları deneme-yanılma yoluyla manuel olarak ayarlanmakta ve sürücüler sürekli aynı frekansta çalışmaktadır. Bu durumda değişken yüke rağmen hava debisi sabit tutulmaktadır ve bu da enerji verimliliğini olumsuz etkilemektedir.

Atmosferden alınarak boya kabinlerine gönderilen havanın istenilen nem $(\approx \% 60$ bağıl nem) ve sıcaklık aralığında olması HVAC ünitelerinin en önemli görevidir. HVAC üniteleri atmosferden alınan havayı 1sıtma, soğutma ve nemlendirme yaparken, enerjiyi en verimli şekilde kullanmaları gerekmektedir. HVAC ünitesinde nemlendirme yaparken enerjiyi verimli kullanabilmek için su püskürtme nozullarının suyu çok iyi şekilde atomize etmesi gerekmektedir. Nozullarda atomizasyonun iyileşmesi, nozullara su basan pompanın enerji tüketimini azaltmaktadır. Ayrıca bu HVAC ünitesi çıkışında havanın nem değerlerinin daha hassas ayarlanmasını sağlayarak, boyamanın kalitesini artırmaktadır.

HVAC ünitelerinde atomizasyonun iyileştirilmesi için suyu daha küçük tane boyutlarında püskürtebilen nozullar ve yüksek basınçlı pompa kullanılmaktadır. Bu uygulamayla havanın şartlandırılması (nemlendirilmesi) daha kolay sağlandığından, HVAC fanlarının debisi düşürülerek enerji tasarrufu sağlanabilir.

\subsection{Chillerler ve Soğutma Kuleleri (Chillers and Cooling Towers)}

Otomotiv sektöründe soğutma sistemleri genellikle boya kabinlerine gönderilen havanın şartlandırılmasında kullanılmaktadır. Otomobil gövdesinin boyanması esnasında açığa çıkan uçucu maddelerin boya kabinlerinden uzaklaştırılması için kabinlerde hava sirkülasyonu yapılmaktadır. Boya kabinlerinde hava sirkülasyonunu sağlamak için dış ortamdan kabine şartlandırılmış hava gönderilmekte ve kabin içinden de ortam havası çekilerek kabin dışına atılmaktadır.

Boya kabinlerine dış ortamdan gönderilen hava belirli sıcaklık ve nem değerinde olmalıdır. Boya kabinine gönderilecek havanın sicaklığı istenilen değerlerin $\left(\sim 25^{\circ} \mathrm{C}\right)$ üzerinde ise soğutma sistemleri (endüstriyel chillerler) vasıtasıyla havanın sıcaklığı düşürülmektedir.

Boyahanelerde soğutma sistemleri, üretim prosesinin vazgeçilmez ekipmanlarındandır. Genellikle otomobil üretim tesislerindeki boyahanede, boya kabinlerine gönderilen havanın şartlandırılmasında chillerlerden gelen soğuk su kullanılmaktadır. Ayrıca, chillerden elde edilen soğuk su, fan-coillere gönderilerek mahal soğutma amacıyla da kullanılmaktadır.

Soğutma sistemlerinde enerji verimliliğinin artırılması için en önemli etkenlerden biri yüksek COP değerine sahip chiller ünitelerinin kullanılmasıdır. Soğutulacak ortama uygun kapasite ve tipte chiller 
seçilmelidir. Genellikle küçük kapasitelerdeki chiller ve soğutucularda hermetik tip kompresörler kullanılmaktadır. Orta kapasitelere $(450 \sim 1.500 \mathrm{~kW}$ arasındaki soğutma kapasitesine) sahip chiller ünitelerinde ise vidalı tip kompresörler tercih edilmektedir. Hermetik ve vidalı kompresörlerle ulaşılması mümkün olmayan yüksek kapasiteleri elde etmek için ise santrifüj kompresör grupları tercih edilmektedir.

Chiller ünitelerinin kondenser kısmında soğutma işlemi hava veya soğutma kulesinden gelen su ile gerçekleştirilmektedir. Chiller ünitelerinin etkinliklerini etkileyen parametreler; soğutma kapasite seçimlerinin uygun ve doğruluğu, kompresör, evaporatör ve kondenserlerin periyodik bakımlarının aksatılmadan gerçekleştirilmesi ve gerekli müdahalelerin uygulanması, yağlama yağı ve soğutucu akışkan seperasyonu, sekonder soğutucu akışkan (hava, su, vb.) hızının artırılması olarak sayılabilir.

Chillerlerin verimlerinin düşük olmasının sebepleri; kondenser ve evaporatörlerin 1sı transfer yüzey alanlarının kirlenmesi, kondenser suyu giriş sıcaklığının yüksek olması (kondenser sıcaklığının $1{ }^{\circ} \mathrm{C}$ düşmesi verimliliği \%2,86 arttırmaktadır.), evaporatör çıkış suyu sıcaklığının düşük olması (soğuk su sıcaklığının $1{ }^{\circ} \mathrm{C}$ artması, verimliliği \%2,45 arttırmaktadır), soğutucu akışkan kaçakları (örneğin; vidanın etrafından soğutucu akışkan sızıntısının meydana gelmesi) ve chillerlerin çok düşük kapasitelerde çalıştırılması olarak ifade edilebilir. Özellikle vidalı ve santrifüj kompresör kullanılan chillerlerde değişken soğutma yüklerinde çalış1lıyorsa, bu kompresöre frekans konvertörü uygulanması chillerlerin verimini artırabilmektedir. Tesislerin soğutma yükü fazla ise birkaç tane vidalı kompresör kullanmaktan ziyade yüksek kapasiteli daha az sayıda santrifüj kompresör kullanan chiller sistemleri tercih edilebilir. Yüksek soğutma kapasitelerinde turbo kompresör kullanan chillerlerde daha yüksek COP değerlerine ulaşlabilmektedir.

İncelenen tesiste; beş adet su soğutmalı, bir adet hava soğutmalı vidalı chillerler bulunmaktadır. Kış aylarında genellikle bir adet, yaz aylarında dört adet chiller birlikte çalışmaktadır. Kısmi yüklerde ( \%25), su soğutmalı chillerlerde yapılan ölçümlerde, chillerlerin COP değerinin 2,22 2,67 arasında değişkenlik gösterdiği hesaplanmıştır. Su soğutmalı bir chiller için hesaplanan bu COP değerleri beklenen aralığın altındadır. Günümüz teknolojisinde su soğutmalı chillerler için COP değerleri genellikle 4,5 7 arasindadır.

Tablo 1. Chiller çalışma parametreleri ve hesaplanan COP değerleri

\begin{tabular}{|c|c|c|c|c|c|c|}
\hline Chiller Ad1 & $\begin{array}{c}\text { Giriş } \\
\text { Sicaklığ } 1{ }^{\circ} \mathrm{C}\end{array}$ & $\begin{array}{c}\text { Ç1k1ş } \\
\text { Sicaklığ1 }{ }^{\circ} \mathrm{C}\end{array}$ & $\begin{array}{c}\text { Debi } \\
\mathrm{m}^{3} / \mathrm{h}\end{array}$ & $\begin{array}{c}\text { Ölçülen Güçç } \\
\mathrm{kW}\end{array}$ & $\begin{array}{c}\text { Soğutma Yükü } \\
\mathrm{kW}\end{array}$ & $\mathrm{COP}$ \\
\hline Chiller 1 & 7,20 & 5,80 & 94,53 & 61,63 & 153,91 & 2,50 \\
\hline Chiller 2 & 6,10 & 4,20 & 94,35 & 79,50 & 208,49 & 2,62 \\
\hline Chiller 3 & 7,50 & 5,90 & 76,00 & 63,80 & 141,42 & 2,22 \\
\hline Chiller 4 & 9,90 & 7,30 & 57,52 & 65,00 & 173,65 & 2,67
\end{tabular}

Mevcut chillerlerin, yeni nesil chiller ile değiştirilmesi durumunda enerji verimliliği artış1 sağlanabilecektir. Chillerlerle ilgili yapılacak satın alımlarda chillerin kısmi ve tam yüklerdeki COP değerlerinin incelenmesi, daha yüksek COP'li cihazların tercih edilmesi işletme maliyetlerini düşürecektir.

\subsection{Boya Firınları (Paint Drying Ovens)}

Boya işlemi 4 kademede gerçekleştirilmektedir. Bu kademeler; kataforez, astarlama, alt kaplama ve üst kaplama (yüzey bitirme) olarak adlandırılmaktadır. Otomotiv sektöründe astarlama ve boyama işlemleri sonucunda elde edilen toplam film kalınlığı genellikle $100-140 \mu \mathrm{m}$ aralığındadır. Tipik bir otomotiv boya prosesinde boya katman kalınlıkları kataforez $20 \mu \mathrm{m}$, astarlama $30 \mu \mathrm{m}$, alt kaplama $15 \mu \mathrm{m}$, üst kaplama $40 \mu \mathrm{m}$ olarak verilebilir [14].

Boya kabinlerinde, araç üzerine yaş olarak uygulanan boyanın, performans ve fonksiyonelliğini sağlamak için, içerisindeki su ve/veya solventin buharlaştırılması gerekmektedir. Bu amaçla, boyama işlemi sonrası, boya kurutma fırınları kullanılmaktadır. Boya kurutma işleminde ihtiyaç duyulan 1sı, ortam havasının doğalgaz yakıtlı brülörlerle 1sıtılması ile sağlanmaktadır. Otomotiv montaj prosesinde, doğalgaz tüketiminin yaklaşı \%70'i, elektrik tüketiminin ise yaklaşık \%50'si boyama prosesinde 
gerçekleşmektedir. Boyama fırınlarında enerji verimliliğin arttırılması için CFD ile 1sı değiştiriclerin modellenmesi ve giriş çıkış akım sıcaklık ve akış düzlemlerinin incelenmesi gibi yaklaşımlar ile tasarımın geliştirilmesi amaçlanmaktadır $[15,16]$.

Enerji verimliliği arttıran uygulamaların başında kurutma firın bacalarından atılmakta olan yüksek sıcakl1ktaki baca gazı atık 1sısının geri kazanılması gelmektedir. Kurutma firını baca gazı hattına reküperatör konularak, firın yakma havasının ön 1sıtılması yapılıp firının doğalgaz tüketimi azaltılabilir. Diğer bir seçenek olarak da firın baca gazı hattına ekonomizör konularak, sıcak su kazanının yükü düşürülebilir, böylece sıcak su kazanında yakıt tasarrufu sağlanabilir.

Kurutma firınlarında gerçekleştirilen baca gazı analizlerinde (sıcaklık, $\mathrm{CO}$ ve $\mathrm{O}_{2}$ oranı tespiti) brülör ayarlarının yapılması ve atık 1sı geri kazanımı ile enerji tasarrufu sağlanabileceği görülmüştür. İncelenen tesiste 30 adet kurutma firınından 18 'inde hava/yakıt oranının optimum değerlerin üzerinde olduğu yapılan ölçümlerle görülmüştür. Bu 18 adet fırının hava/yakıt oranının optimizasyonu ile yıllık 4.410.360 kWh/yıl mali olarak 167.371 \$/yıl enerji tasarrufu sağlanabilecektir.

Yapılan incelemelerde boyahane kurutma firınlarının 21 tanesinde baca gazı sıcaklığ $200-360^{\circ} \mathrm{C}$ arasında (ortalama $283^{\circ} \mathrm{C}$ ) baca gazı debisi $1.300-2.500 \mathrm{~m}^{3} / \mathrm{h}$ arasında (ortalama $1.935 \mathrm{~m}^{3} / \mathrm{h}$ ) olduğu tespit edilmiştir. Fırın bacalarındaki atık 1sı potansiyelinin belirlenmesi için teknik ve ekonomik analizler yapıldığında, sistemin atık ısı geri kazanımına oldukça uygun olduğu saptanmıştır.

İncelenen 21 adet boya kurutma firınından 18 adedinde, hava/yakıt oranının optimize edilmesi gerektiği görülmüştür. Hava/yakıt oranı ayarlandıktan sonra gerçekleşecek baca gazı debisine göre enerji tasarruf potansiyeli hesaplanmıştır. 21 adet boya kurutma firınından atık 1sı geri kazanımı için reküperatör uygulanmas1 durumunda yıllık $6.168 .710 \mathrm{kWh} / \mathrm{y} 1 \mathrm{l}$ ve mali olarak 234.098 \$/y1l enerji tasarrufu sağlanabilecektir.

\subsection{Su Pompaları (Water Pumps)}

Otomobil üretim tesislerinde, su pompalarını birçok farklı uygulamada görmek mümkündür. Su pompalarının uygulandığı noktalar genel olarak aşağıdaki şekilde özetlenebilir;

- Su tasfiye pompaları; yer altı kuyularından ve şehir şebekelerinden çekilen suyun fabrikada kullanım noktalarına gönderilmesi için kullanılmaktadır.

- Kompresör soğutma suyu pompaları; su soğutmalı basınçlı hava kompresörlerinin soğutulmasında soğutma kulesi ile kompresör arasında su sirkülasyonunu sağlamaktadır.

- HVAC üniteleri nemlendirme pompaları; HVAC ünitelerinden, boya kabinine gönderilen havanın nemlendirilmesi için nozullara basınçlı şekilde su göndermektedir.

- Isitma sistemi pompalari; HVAC, ortam 1sitmas1, kazan ve 1sitılacak ortam arasinda sicak su sirkülasyonunu sağlamaktadır.

- Soğutma sistemi pompaları; HVAC, ortam soğutmasında, chiller ve soğutulacak ortam arasında soğuk su sirkülasyonunu sağlamaktadır.

- Buhar kazanı besi suyu pompaları; Buhar kazanına gönderilen suyun kazan işletme basıncına kadar basınçlandırılması için kullanılmaktadır.

Kompresör soğutma suyu pompaları, kompresörden açığa çıkan ısının soğutma kulesinden atmosfere atılması için soğutma suyu dolaşımını sağlamaktadır. Kompresör soğutma sisteminde toplam üç adet pompa bulunmaktadır. Pompaların biri aktif olarak çalışırken, ikisi yedek beklemektedir. Aktif çalı̧̧an kompresörün soğutma suyu debi ihtiyacı yaklaşık $70 \mathrm{~m}^{3} / \mathrm{h}$ iken mevcut aktif pompanın debisi 140-145 $\mathrm{m}^{3} /$ h'dir. Yapılan analizde devrede olmayan iki yedek kompresör içerisinde su dolaştırıldığ 1 tespit edilmiştir. Aktif çalışan kompresörün soğutulmasını sağlamak için düşük kapasiteli, yüksek verimli pompaların kullanılmasıyla $204.049 \mathrm{kWh} / \mathrm{y} 1$ enerji tasarrufu mümkündür. Yedek kompresörlerin girişine uygun vana sistemi yerleştirilerek bu hatların ihtiyaç halinde kullanılacak şekilde yeniden tasarımı mümkündür. Toplam tasarrufun mali değeri 14.538 \$/yıl'dır. Yapılacak yatırımın mali değeri 21.167 \$'dir. Basit geri ödeme süresi ise 1,46 yıl'dır. 
Su tasfiye pompaları, fabrikanın su ihtiyacını karşılamak amacıyla kuyu ve şehir şebekesinden aldığı suyu yumuşatma ünitesinden geçirdikten sonra kullanım alanlarına beslemeye yarayan ekipmandır. Su tasfiye pompaları toplamda beş adet olup, aktif olarak iki adedi eşzamanlı çalışmaktadır. Su tasfiye ünitesinde bulunan endüstriyel beşli grup pompaların verimlerinin düşük olduğu (\%36-43) belirlenmiştir. Mevcut pompaların daha verimli (>\%60) pompalar ile değişimi sonucunda $46.275 \mathrm{kWh} / \mathrm{y} 1 \mathrm{l}$ enerji tasarrufu yapmak mümkün olacaktır. Bu tasarrufun mali değeri 3.296 \$yıl'dır. Bu değişimin yatırım maliyeti $9.845 \$$ yıl ve basit geri ödeme süresi ise yaklaşık 3 yıldır.

\section{SONUÇLAR (CONCLUSIONS)}

Endüstriyel üretimin sürdürülebilir gelişmesi enerji verimliliğinin arttırılmasına bağlıdır. Bu çalışma kapsamında otomotiv sektöründe enerji verimliliği çözümleri incelenmiştir. Çalışma gerçekleştirilirken otomotiv yan sanayi ve parça tedarik süreçleri dikkate alınmamıştır. Tesisin ana ekipmanları (boyahane, kurutma firınları vb.) ve yardımcı tesisler (basınçlı hava, soğutma vb.) çalışma kapsamında incelenmiştir.

Çalışma binek araç için BiW üretimi, boyama işlemi, şase ve aksesuar montaj işlemlerini içeren bir montaj tesisinde gerçekleştirilmiştir. Çalışma kapsamında tesiste bulunan; buhar ve su kazanları, basınçlı hava, Boyahane HVAC fan, çiller ve soğutma kulesi, boya firınları, su pompaları sistemlerinin enerji tüketimleri ve bu sistemlerde gerçekleştirilebilecek enerji verimliliği çözümleri incelenmiştir.

Buna göre buhar kazanlarında Hava/Yakıt oranı optimizasyonu ile $146.610 \mathrm{kWh} / \mathrm{y} 1 \mathrm{l}$ tasarruf potansiyeli bulunmuştur. Buhar kazanlarının baca gazı atık 1sısı ile besi suyu ön 1sıtması yapabileceği tespit edilmiştir. Her iki kazan için ekonomizer uygulanması durumunda $121.968 \mathrm{kWh} / \mathrm{y} 1 \mathrm{l}$ doğalgaz tasarruf potansiyeli tespit edilmiştir. Yatırımın geri ödeme süresi ise 5,4 yıldır.

Sıcak su kazanlarında atık 1sı kullanımı ile $144.100 \mathrm{kWh} / \mathrm{y} 1 \mathrm{l}$ tasarruf potansiyeli tespit edilmiştir. Bu yatırımın geri ödeme süresi ise 5,09 yıldır. Kazanlarda atık 1s1 geri kazanımı ve hava/yakıt oranının optimizasyonu ile toplam $412.678 \mathrm{kWh} / \mathrm{y} 1$ enerji tasarrufu imkânı sağlanabilir.

Basınçlı Hava sistemleri incelemesinde ise hava hatlarında sızıntılar bulunduğu ve kompresör kapasite kontrolünde verimsiz yöntemler uygulandığı tespit edilmiştir. Gövde (74 adet) ve Trim (56 adet) bölümlerinde yer alan toplam 130 adet sızıntı noktasının tamir edilmesi sonucunda $(209.010+134.030)$ $343.040 \mathrm{kWh} / \mathrm{y} 1 \mathrm{l}$ elektrik enerjisi tasarruf potansiyeli belirlenmiştir.

Tesisteki 9 bar basınçlı hava talebi bir adet $90 \mathrm{~kW}$ gücünde frekans kontrollü ve bir adet $75 \mathrm{~kW}$ gücünde yük/boş kontrollü kompresör tarafından sağlanmaktadır. Ana kompresör olarak çalışan $90 \mathrm{~kW}$ gücündeki kompresörün kapasitesinin yeterli gelmediği, bu nedenle $75 \mathrm{~kW}$ gücündeki kompresörün çok sık devreye girdiği tespit edilmiştir. Bu durumda kompresörün yıllık çalışma süresinin \%60'ında boşta çalıştı̆̆ ve boşta çalışma sırasında $25 \mathrm{~kW}$ anlık enerji tüketimi olduğu ölçülmüştür. Bu kayıpların önlenmesi için 132 $\mathrm{kW}$ gücünde, frekans kontrollü tek kompresör ile tesis için gerekli olan ve 9 bar basınç değerindeki tüm basınçlı hava ihtiyacının karşılanabileceği görülmüştür. Bu basınçlı hava sisteminde boşta çalışmayı ortadan kaldırmak için yeni satın alınacak VSD'li bir kompresörün geri ödeme süresi 5 yılı geçecektir. Dolayısıyla, sadece enerji tasarrufu yapmak için yeni bir kompresör satın almak yerine, ekonomik çalışma ömrünü dolduran bir kompresörün, boşta çalışmay1 önleyecek yeni bir kompresör ile değiştirilmesi uygulanabilir ekonomik çözüm olacaktır.

Boyahane HVAC fanlarında yapılan incelemede, fanların frekans kontrol donanımına sahip olduğu görülmüştür. Fakat HVAC fanlarının kapasite kontrolü ölçüme dayalı olarak yapılmamaktadır. Fan devri operatör tarafından tecrübeye dayalı olarak elle ayarlanmaktadır. Bu durumda boya kabinine gönderilmesi gerek taze hava miktarı, boya kabinindeki hava kalitesine (boya partikül sayısı vb.) göre anlık olarak ayarlanamamaktadır.

Tesiste yer alan su soğutmalı, vidalı kompresör kullanan chillerlerde, kısmi yüklerde $(\sim \% 25)$ alınan ölçümlere göre yapılan hesaplarda chillerlerin COP değerinin 2,22 2,67 arasında değiştiği görülmüştür. Günümüz teknolojisinde su soğutmalı chillerler için COP değerleri genellikle 4,5 7 arasındadır.

İncelenen tesiste yer alan 30 adet boya kurutma firınından 18 adedinde, hava/yakıt oranının optimize edilmesi gerektiği, 21 adedinde ise atık ısı kullanım fizibilitesinin uygun olduğu görülmüştür. Hava/yakıt oranı ayarlandıktan sonra gerçekleşecek baca gazı debisine göre enerji tasarruf potansiyeli hesaplanmıştır. 
21 adet boya kurutma firınından atık 1sı geri kazanımı için sisteme reküperatör uygulanması durumunda $6.168 .710 \mathrm{kWh} / \mathrm{y} 11$ doğalgaz (1s1l enerji) tasarrufu sağlanabilecektir.

İncelen su pompalarının kompresör soğutma suyu devir daimi için kullanıldığı görülmüştür. Kompresör sisteminde yer alan üç adet kompresörden biri aktif çalışırken iki kompresör yedek beklemekte doğal olarak soğutma ihtiyaçları olmamaktadır. Yapılan incelemede boş durumda olan kompresörlerde de su devir daimi yapıldığ 1 görülmüştür. Yedek kompresörleri besleyen pompaların sadece soğutma ihtiyacı olduğunda çalışacak şekilde düzenlenmesi ile enerji verimliliği sağlanmaktadır. Bu uygulama ile 204.049 $\mathrm{kWh} / \mathrm{y} ı 1$ elektrik enerjisi ve mali tasarruf sağlanabilecektir. Yatırımın geri ödeme süresi ise 4,5 yıldır. Tesiste yer alan düşük verimli (\%36-43) su tasfiye pompalarının daha yüksek verimli ( $>\% 60)$ pompalar ile değişimi sonucunda $46.275 \mathrm{kWh} / \mathrm{y}$ 1 enerji tasarrufu yapmak mümkün olacaktır. Bu yatırımın geri ödeme süresi ise yaklaşık 3 yıldır.

Yapılan incelemelere göre tavsiye edilen uygulamalar ile sağlanacak olan toplam elektrik enerjisi tasarrufu $593.364 \mathrm{kWh}$ 'tir ve bunun mali değeri $42.275 \$$ yil'dir. Toplam 1 sil enerji tasarrufu 6.581 .388 kWh'tir ve bunun mali değeri 308,182 \$/yıl'dır. Tüm iyileştirmeler için gerekli yatırım maliyeti 738,737 \$'dir. Önerilen çalışmaların toplam geri ödeme süresi yaklaşık 2,5 yıl'dır. Tüm bu tasarruf önlemleri gerçekleştirildiğinde tesisin SETe değeri $275 \mathrm{kWh}$ den 272,3 kWh'e, SETdg değeri $578 \mathrm{kWh}$ den 545,1 kWh'e düşecektir.

\section{SIMGELER ve KISALTMALAR (SYMBOLS AND ABBREVIATIONS)}

$\begin{array}{ll}\text { BiW } & \text { Araç Gövdesi } \\ \text { COP } & \text { Soğutma Tesir Katsayısı } \\ \text { CO } & \text { Karbon Monoksit } \\ \text { DEA } & \text { Veri Zarflama Analizi } \\ \text { HVAC } & \text { Isıtma Havalandırma İklimlendirme } \\ \text { O }_{2} & \text { Oksijen } \\ \text { SET } & \text { Spesifik Enerji Tüketimi } \\ \text { SET }_{\mathbf{e}} & \text { Spesifik Elektrik Enerjisi Tüketimi } \\ \text { SET }_{\text {dg }} & \text { Spesifik Doğalgaz Tüketimi } \\ \text { SFA }_{\text {VOC }} & \text { Stokastik Sınır Analizi } \\ \text { VSD } & \text { Uçucu Organik Bileşen } \\ \end{array}$

\section{KAYNAKLAR (REFERENCES)}

[1] "Climate Change: Basic Information," 2017. [Online]. Available: https://www.epa.gov/climatechange/climate-change-basic-information. [Erişim Tarihi: 26-Nisan-2017].

[2] P. Enderle, O. Nowak, J. Kvas, Potential alternative for water and energy savings in the automotive industry: Case study for an Austrian automotive supplier. J. Clean. Prod, 34 (2012) 146-152

[3] A. Fysikopoulos, D. Anagnostakis, K. Salonitis, G. Chryssolouris, An empirical study of the energy consumption in automotive assembly. Procedia CIRP, 3:1 (2012) 477-482.

[4] J. L. Rivera, T. Reyes-Carrillo, A framework for environmental and energy analysis of the automobile painting process. Procedia CIRP, 15 (2014) 171-175. 
[5] S. C. Oh, A. J. Hildreth, Estimating the technical improvement of energy efficiency in the automotive industry-stochastic and deterministic frontier benchmarking approaches. Energies, 7:9 (2014) $6196-6222$.

[6] I. Schlei-peters et al., Assessing Combined Water-Energy-Efficiency Measures in the Automotive Industry. Procedia CIRP, 29 (2015) 50-55.

[7] Various, Technology Roadmap for Energy Reduction in Automotive Manufacturing. USA Department of Energy, (2008).

[8] C. Galitsky, E. Worrell, Energy Efficiency Improvement and Cost Saving Opportunities for the Vehicle Assembly Industry. An Energy Star Guide for Energy and Plant Managers, 2008.

[9] J. L. Rivera, T. Reyes-Carrillo, A life cycle assessment framework for the evaluation of automobile paint shops. J. Clean. Prod., 115 (2016) 75-87.

[10] B. Leven, C. Weber, Energy efficiency in innovative industries: Application and benefits of energy indicators in the automobile industry. Proc. ACEEE Summer Study Energy Effic. Ind., 1 (2001) $67-75$.

[11] P. Dehning, S. Thiede, M. Mennenga, C. Herrmann, Factors influencing the energy intensity of automotive manufacturing plants. J. Clean. Prod., 142 (2017) 2305-2314, 2017.

[12] D. Kaya, P. Phelan, D. Chau, H. Ibrahim Sarac, Energy conservation in compressed-air systems. Int. J. Energy Res., 26:9 (2002) 837-849.

[13] S. Sapmaz et al., Selection of compressors for petrochemical industry in terms of reliability, energy consumption and maintenance costs examining different scenarios. Energy Explor. Exploit. 33:1 (2015) 43-62.

[14] J. Domnick, D. Gruseck, K. Pulli, A. Scheibe, Q. Ye, F. Brinckmann, Investigations of the drying process of a water based paint film for automotive applications. Chem. Eng. Process. Process Intensif., 50:5-6 (2011) 495-502.

[15] P. P. Rao, A heat exchanger analogy of automotive paint ovens. Appl. Therm. Eng., 61:2 (2013) 381-392.

[16] S. Niamsuwan, P. Kittisupakorn, and A. Suwatthikul, "Enhancement of energy efficiency in a paint curing oven via CFD approach: Case study in an air-conditioning plant," Appl. Energy, 156 (2015) $465-477$. 